\title{
Serotyping and Antimicrobial Susceptibility Pattern of Avian Pathogenic Escherichia coli
}

\author{
D. M. Muglikar ${ }^{1 *}$, I. H. Kalyani ${ }^{1}$, Dhruv Desai ${ }^{1}$, J. M. Patel $^{2}$, D. R. Patel $^{1}$, \\ Pushpa Makwana ${ }^{1}$ and J. B. Solanki ${ }^{3}$
}
${ }^{1}$ Department of Veterinary Microbiology, ${ }^{2}$ Department of Veterinary Pathology, ${ }^{3}$ Department of Veterinary Parasitology, College of Veterinary Sciences and Animal Husbandry, Navsari, (Gujarat), India

*Corresponding author

\begin{tabular}{|l|}
\hline K e y w o r d s \\
Ampicillin (AMP), \\
Enrofloxacin (EX), \\
Aerobactin, \\
Iroproteins, \\
Yersiniabactin
\end{tabular}

A B S T R A C T
Poultry industry in India is facing major economic setback due to persistent disease problems like colibacillosis. The incidence and severity extra intestinal infection like complicated chronic respiratory disease have increased rapidly. In this context the role of E.coli in causing extra intestinal infection needs to be explored. The study of virulence determinants associated with these bacteria help us in understanding the pathogenic mechanism of disease. The role of various serotypes associated with extra intestinal infection needs further studies. With this view this research was conducted on total 77 E. coli which were isolated from 228 tissue samples collected from dead birds suffering with colibacillosis. Out of 228 tissue samples a maximum numbers (41) $53.24 \%$ of E.coli isolates were recovered from Navsari Dist. of Gujarat Followed by (36) $23.84 \%$ from Anand Dist. of Gujarat. All these 77 E. coli isolates were tested for susceptibility to eight suitable antibiotics by disc diffusion method. As per antibiogram pattern the antibiotic drug resistance was highest to Penicillin (P), 77 (100\%), and Oxytetracycline (O), 77 (100\%), followed by 74 (96.10\%) to Ampicillin (AMP), Enrofloxacin (EX), 70 (90.90\%), Streptomycin (S), 64 (83.11\%), Chloramphenicol (C), 65 (84.41\%), Gentamicin (GEN), 59 (76.62\%) whereas only 20 (25.97\%) isolates were resistant to Cefatrixone (CTR). All these isolates were tested for invasiveness by Congo red binding test, $64(83.11 \%)$ showed red colonies after 48 hrs of incubation at room temperature and were found to be invasive, while 13 (16.88\%) showed colorless colonies turned out to be negative (non-invasive) for Congo red binding test. The Serotyping of selected 43 isolates was done at NSEC, CRI, Kasauli (HP). India. The results revealed UT (6), $\mathrm{O}_{88}(6), \mathrm{O}_{83}(4), \mathrm{O}_{126}(1), \mathrm{O}_{49}$ (3), $\mathrm{O}_{145}(2)$ and $\mathrm{O}_{84}(5), \mathrm{O}_{7}(2), \mathrm{O}_{157}(9), \mathrm{O}_{8}(4), \mathrm{O}_{119}(1)$, Among these serotypes the most frequent serotypes detected were $\mathrm{O}_{157}(9) \mathrm{O}_{88}(6)$, UT (6), $\mathrm{O}_{84}(5), \mathrm{O}_{8}(4), \mathrm{O}_{49}(3)$, $\mathrm{O}_{145}(2), \mathrm{O}_{7}(2)$,. 


\section{Introduction}

Poultry is one of the fastest growing livestock sector in India with around eight percent growth rate per annum. The application of new technologies resulted in the multifold and multifaceted growth of this sector.

In spite of all the measures, the poultry industry in India suffers a major setback due to the disease outbreaks. The incidence and severity of colibacillosis have increased rapidly and it is likely to be a major problem in the poultry industry., E. coli grouped as (a) commensal $E$. coli (b) intestinal pathogenic $E$. coli and (c) extra intestinal pathogenic E. coli. The strains that are responsible for extra intestinal infections are termed as extra intestinal pathogenic E. coli (ExPEC) (Russo and Johnson 2000). There are six phylogenetic group A, B1, B2, C, D and E, Most of the ExPEC strains phylogenetically belong to B2 and to a lesser extent D groups (Smith et al., 2007.)

The diversity of serotypes associated with colibacillosis was reported by (Landman et al.,2014). In Europe, six serogroups (O1, O2, O5, O8, O18 and O78) were accounted for $56.5 \%$ of APEC isolates and $22.5 \%$ of nonpathogenic isolates (Schouler et al., 2012).

The differentiation of pathogenic and nonpathogenic strains of E.coli is made on the basis of the virulence attributes, including those encoding for adhesions (F1, P, and stg fimbriae, curli, and EA/I), anti-host defense factors (ompA, iss, lipopolysaccharide, and $\mathrm{K} 1$ ), iron acquisition systems (aerobactin, iroproteins, yersiniabactin, and the sit iron acquisition locus), auto transporters (tsh,vat, and aatA).

The indiscriminate use of antibiotics for prevention of early chick mortality resulted in rapid spread of antimicrobial resistance among avian Escherichia coli. In order to devise a strategy to deal with them, antimicrobial resistance pattern of E.coli associated with extra intestinal infection was studied.

\section{Materials and Methods}

\section{Collection of samples}

In this study a total of 228 tissue swab viz. liver, heart, lung, kidney, spleen were aseptically collected from freshly dead chicken after postmortem examination.

All samples were transferred to the microbiology laboratory under chilled condition. All the work involving handling of E. coli organism and infected tissue material was performed by taking appropriate biosafety precautions and following all aseptic conditions

\section{Isolation and identification}

All tissue swabs were inoculated directly on MacConkey agar and on Eosin methylene blue agar (EMB) and incubated at $37^{\circ} \mathrm{C}$ for 16 $18 \mathrm{hrs}$. When evidence of growth was observed in the form of Lactose fermenting pinkish colonies on MAC and Metallic sheen with dark centered colonies on EMB; further identification was carried out on Chromogenic E.coli Agar. Colonies showing blue color were considered as E. coli and further identification was carried out by conventional and commercial biochemical test kit.

\section{Congo Red (CR) binding assay}

The phenotypic characterization of E. coli isolates for determination of their invasiveness property was carried out by using Congo Red (CR) binding assay, with the objective of distinguishing between pathogenic and nonpathogenic microorganisms as described by (Berkhoff and Vinal, 1986). 


\section{Antibiotic sensitivity test}

The antibiotic sensitivity test was carried out for all E.coli isolates as per method described by Bauer et al., (1966).

\section{Serotyping of $E$. coli isolates}

Total 43 multidrug resistant E.coli isolates were sent for Serotyping at NSEC, CRI, Kasauli (HP). India.

\section{Results and Discussion}

In this chapter results of different test are presented systematically. Wherever deemed fit data have been tabulated. The results, their rationales, outcome, have been discussed in the light of set doctrines and work of other researchers on the topic Total 228 tissue samples were collected from dead birds affected with colibacillosis. All the samples were processed by following standard bacteriological procedure in the department of Veterinary Microbiology. The recovery rate of E. coli from total of 228 tissue samples was 77 $(33.77 \%)$. (Table 1). Identification of all recovered isolates was done using biochemical test. All E.coli showed biochemical profile as Indole positive MR positive, VP negative, Citrate negative, Oxidase negative and Catalase positive reactions. A maximum numbers (41) $53.24 \%$ of E.coli. isolates were recovered from tissue specimens collected from dead birds of poultry farms located in Navsari Dist. of Gujarat Followed by (36) $23.84 \%$ from Anand Dist. of Gujarat. The findings of this research work are in agreement with findings of Archna mishra et al.,(2002), Veere Gowda et al., (1996) and Saha et al.,(2007) who reported $20.00 \%$, $23.80 \%$ and $28.93 \%$ prevalence of avian $E$. coli. Whereas Rajasekaran (2001) and Sharada et al., (2001) reported $58.00 \%$ and $76.47 \%$ recovery rate for $E$. coli isolated from colibacillosis affected birds. All 77 E. coli isolates recovered from Colibacillosis were tested for susceptibility to eight suitable antibiotics by disc diffusion method. Out of 77 isolates of $E$. coli, the antibiotic drug resistance was highest to Penicillin (P), 77 (100\%), and Oxytetracycline (O), 77 (100\%), followed by 74 (96.10\%) to Ampicillin (AMP), Enrofloxacin (EX), 70 (90.90\%), Streptomycin (S), $64 \quad(83.11 \%)$, Chloramphenicol (C), $65 \quad(84.41 \%)$, Gentamicin (GEN), 59 (76.62\%) whereas only $20(25.97 \%)$ isolates were resistant to Cefatrixone (CTR) (Table 3). Multiple drug resistance was observed in all isolates of $E$. coli. The highest sensitivity $(74.02 \%)$ observed to Cefatrixone (CTR) followed by Gentamycin (G) (23.37 \%), Streptomycin (16.88\%) and Chloraphenicol (C) (23.37\%). Our findings are in agreement with Sahoo et al., (2012). who reported high resistance to commonly used antibiotics like Chlortetracycline (88.58\%), Ampicillin (74.29\%), Tetracycline (74.29\%), Streptomycin (85.72\%), Penicillin-G (82.86\%), Amikacin (82.86\%), Furazolidone (77.14\%), Amoxicillin (71.43\%) and Cotrimoxazole $(71.43 \%)$, similar findings of multiple drug resistance were also recorded by(Mohamed et al., and Radwan et al., 2014).The highest resistance to Oxytetracycline was also recorded during this study. This resistance is principally plasmid mediated and an inducible trait. Mechanisms of resistance include decreased accumulation of tetracycline due to either acquisition of an energy-dependant efflux path way or to decreased influx, or to decrease access of tetracycline to the ribosome (site of action) due to acquisition of ribosome protected proteins and enzymic inactivation bacteria that have been resistant to one tetracycline frequently exhibit resistance to the other tetracyclines. In this study, $96.10 \%$ per cent resistant to, Ampicillin was recorded which may be attributed to the production of $\beta$ lactamase group of enzymes, which have been 
reported in high percent Tetracycline and Streptomycin have been utilized for several decades, The present study from south Gujarat region of India also indicates highest $100 \%$ resistance to Oxytetracycline and $83.11 \%$ to Streptomycin therefore, preventive and therapeutic effects on APEC strains should no longer be expected from these antibiotics. The antibiogram patterns differ from nation to nation and even within different regions of nation as a result of exposures to different antibiotics. There is strong correlation between expression of CR phenotype and virulence in avian E. coli (Berkhoff and Vinal 1986), they suggested that it was associated with the presence of $\mathrm{p}$-D-glucan in bacterial cell wall.

The characteristic of $\mathrm{CR}$ binding constitutes a moderately stable, reproducible and easily distinguishable phenotypic marker. Out of 77 E. coli isolates tested for invasiveness by Congo red binding test, 64 (83.11\%) showed red colonies after $48 \mathrm{hrs}$ of incubation at room temperature and were found to be invasive, while 13 (16.88\%) showed colorless colonies turned out to be negative (non-invasive) for Congo red binding test (Table 4) The present results are in agreement with earlier observations of (Berkhoff and Vinal 1986, Deshmukh and Karpe 2006) who opined that the test distinguished between invasive and non-invasive serotypes of $E$. coli. The similar findings for Congo red binding activity were observed by Aziz et al., (1995) and Seifi et al., (2015). They reported $82.6 \%$ and $88.75 \%$ CR positive E. coli strains, respectively. Whereas, Berkhoff and Vinal (1986) Shankar et al., (2010) and Bashar et al., (2011) reported $100 \%, 98.47 \%$ and $69 \%$ of $E$. coli isolates with CR binding activity respectively.

The Serotyping of all the 42 isolates was done at NSEC, CRI, Kasauli (HP). India. The results revealed UT (6) $13.95 \%, \mathrm{O}_{88}$ (6) $13.95 \%, \mathrm{O}_{83}$ (4) $9.30 \%, \mathrm{O}_{126}$ (1) $2.32 \%, \mathrm{O}_{49}$ (3) $6.97 \%, \mathrm{O}_{145}(2) 4.65 \%$ and $\mathrm{O}_{84}(5) 11.62 \%$, $\mathrm{O}_{7}$ (2) $4.65 \%, \mathrm{O}_{157}(9) 20.60 \%, \mathrm{O}_{8}$ (4) $9.30 \%$, $\mathrm{O}_{119}(1) 2.32 \%$ (Table 2).

Among these serotypes the most frequent serotypes detected were $\mathrm{O}_{157}(9) \mathrm{O}_{88}$ (6), UT (6), $\mathrm{O}_{84}(5), \mathrm{O}_{8}(4), \mathrm{O}_{49}(3), \mathrm{O}_{145}(2), \mathrm{O}_{7}(2)$, The occurrence of different $E$. coli serotypes in coli septicaemia was reported from time to time by various researchers viz., Ghosh (1989); Krishnamohan Reddy et al., (1994a); They opined that the outbreaks of the disease might be influenced by extent of intensity of the various strains present in the environment.

The findings of present research work are in agreement with those of Ashraf et al., (2015) who also reported O157 and UT (untypable) serotypes from chicken.

Table.1 Recovery rate of $E$. coli from tissue samples

\begin{tabular}{|c|c|c|}
\hline Total no of tissue & No .of pure E.coli & Percentage \\
samples & isolates & $\mathbf{3 3 . 7 7 \%}$ \\
\hline 228 & $\mathbf{7 7}$ & $\mathbf{3 7}$ \\
\hline
\end{tabular}


Table.2 Serotyping test results

\begin{tabular}{|c|c|c|c|c|}
\hline $\begin{array}{c}\text { Sr. } \\
\text { No. }\end{array}$ & Serotype & $\begin{array}{c}\text { Total no of } \boldsymbol{E} . \mathbf{c o l i} \\
\text { isolates send for } \\
\text { serotyping }\end{array}$ & $\begin{array}{c}\text { Total no of specific } \\
\text { serotypes identified }\end{array}$ & $\begin{array}{c}\text { Percentage of specific } \\
\text { serotype identified }\end{array}$ \\
\hline $\mathbf{1}$ & UT & 43 & 6 & $13.95 \%$ \\
\hline $\mathbf{2}$ & $\mathbf{O}_{\mathbf{8 8}}$ & 43 & 6 & $13.95 \%$ \\
\hline $\mathbf{3}$ & $\mathbf{O}_{\mathbf{8 3}}$ & 43 & 4 & $9.30 \%$ \\
\hline $\mathbf{4}$ & $\mathbf{O}_{\mathbf{1 2 6}}$ & 43 & 1 & $2.32 \%$ \\
\hline $\mathbf{5}$ & $\mathbf{O}_{\mathbf{1 4 5}}$ & 43 & 2 & $4.65 \%$ \\
\hline $\mathbf{6}$ & $\mathbf{O}_{\mathbf{8 4}}$ & 43 & 5 & $11.62 \%$ \\
\hline $\mathbf{7}$ & $\mathbf{O}_{\mathbf{7}}$ & 43 & 2 & $4.65 \%$ \\
\hline $\mathbf{8}$ & $\mathbf{O}_{\mathbf{1 5 7}}$ & 43 & 9 & $18.60 \%$ \\
\hline $\mathbf{9}$ & $\mathbf{O}_{\mathbf{8}}$ & 43 & 4 & $9.30 \%$ \\
\hline $\mathbf{1 0}$ & $\mathbf{O}_{\mathbf{1 1 9}}$ & 43 & 1 & $2.32 \%$ \\
\hline $\mathbf{1 1}$ & $\mathbf{O}_{\mathbf{4 9}}$ & 43 & 3 & $6.97 \%$ \\
\hline
\end{tabular}

Table.3 Antibiotic sensitivity test results

\begin{tabular}{|c|c|c|c|c|c|c|}
\hline $\begin{array}{c}\text { Sr. } \\
\text { no. }\end{array}$ & $\begin{array}{c}\text { Antimicrobial } \\
\text { agents(Concentration) }\end{array}$ & $\begin{array}{c}\text { Total } \\
\text { no }\end{array}$ & Sensitive & $\%$ & Resistant & $\begin{array}{c}\% \\
\text { Resistance }\end{array}$ \\
\hline $\mathbf{1}$ & Penicillin (P) (10mcg) & 77 & 0 & $0 \%$ & 77 & $100 \%$ \\
\hline $\mathbf{2}$ & Oxytetracycline (0) (30mcg) & 77 & 0 & $0 \%$ & 77 & $100 \%$ \\
\hline $\mathbf{3}$ & Ampicillin (AMP) (10mcg) & 77 & 3 & $3.89 \%$ & 74 & $96.10 \%$ \\
\hline $\mathbf{4}$ & Enrofloxacin (EX) (10mcg) & 77 & 7 & $9.09 \%$ & 70 & $90.90 \%$ \\
\hline $\mathbf{5}$ & Chloraphenicol (C) (10mcg) & 77 & 12 & $15.58 \%$ & 65 & $84.41 \%$ \\
\hline $\mathbf{6}$ & Sreptomycin (S) (10mcg) & 77 & 13 & $16.88 \%$ & 64 & $83.11 \%$ \\
\hline $\mathbf{7}$ & Gentamycin (G) (10mcg) & 77 & 18 & $23.37 \%$ & 59 & $76.62 \%$ \\
\hline $\mathbf{8}$ & Cefatrixone (CTR) (10mcg) & 77 & 57 & $74.02 \%$ & 20 & $25.97 \%$ \\
\hline
\end{tabular}

Table.4 Congo Red binding assay results

\begin{tabular}{|c|c|c|c|c|}
\hline $\begin{array}{c}\text { Total no of } \\
\text { E.coli }\end{array}$ & $\begin{array}{c}\text { E.coli Positive for } \\
\text { Congo red }\end{array}$ & $\begin{array}{c}\text { E.coli } \\
\% \text { positive }\end{array}$ & $\begin{array}{c}\text { E.coli } \text { Negative for } \\
\text { Congo red }\end{array}$ & $\begin{array}{c}\text { E.coli } \% \\
\text { negative }\end{array}$ \\
\hline 77 & 64 & $83.11 \%$ & 13 & $16.88 \%$ \\
\hline
\end{tabular}

\section{Acknowledgment}

The Authors thanks the Dean, of Vanbandhu College of Veterinary Sciences and Animal Husbandry, Navsari Agricultural University, and Navsari for providing necessary facilities for this study.

\section{References}

Archana Mishra, Rakesh S, Dalijeet C and Tanwani S K (2002) Antibiogram of Escherichia coli Isolates from Domestic Poultry. Indian Veterinary Journal, 79: 863 - 864. 
Ashraf, A. A., M. A. Ahmed, S. A. Nasef and R. M. Reda (2015) Antibacterial resistance and resistance gene detriments of $E$. coli isolated from chicken. Benha Veterinary Medical Journal, 28(2): 231-240.

Aziz, S. A., H. Roshdy and M. Refai (1995) A study of phenotypic and genotypic virulence markers of Escherichia coli isolated from poultry. National laboratory for veterinary quality control on poultry production, AHRI, Dokki, Giza. Department of Microbiology, Faculty of Veterinary Medicine, Cairo University, 1-24.

Bashar, T., M. Rahman, F. A. Rabbi, R. Noor and M. Majibur Rahman (2011) Enterotoxin profiling and antibiogram of Escherichia coli isolated from poultry faeces in Dhaka District of Bangladesh. Stamford journal of microbiology, 1(1):51-57.

Berkhoff H. A. and Vinal A. C. (1986) Congo red Medium to Distinguish Between Invasive and Non-Invasive Escherichia coli Pathogenic for Poultry. Avian Diseases 30: 116-121.

Bauer, A.W., W. M. M. Kirby, J. C. Sherris and M. Turck (1966) Antibiotic susceptibility testing by a standardized single disk method. American journal of clinical pathology, 45(4): 493-6.

Deshmukh and Karpe A G (2006) Study of virulence factors of Escherichia coli from Domestic animals and poultry. Indian Journal of Comparative Microbiology, Immunology Infections Diseases 27: 48-49.

Ghosh S. S. (1989) Incidence of Escherichia coli serotypes of animals and avian origins in North- Eastern hills region. Indian Journal of Animal Sciences 59: 1079-1082.

Krishna Mohan Reddy, Koteewaran Y and Dorairajan N (1994) Characterization of Escherichia coli isolates from
Pathological conditions of Poultry. Indian Veterinary Journal 71: 209212.

Landman W.J., Buter G.J., Dijkman R. (2014). Molecular typing of avian pathogenic Escherichia coli colonies originating from outbreaks of $E$. coli peritonitis syndrome in chicken flocks Avian Pathol 433:45-56.

Mohamed, M. A., A. S. Mostafa and E. Rafeek (2014) Virulence genes content and antimicrobial resistance in Escherichia coli from broiler chickens. Veterinary Medicine International, Hindawi Publishing Corporation 1:1-6.

Radwan, I. A., H. H. Salam, S. A. AbdAlwanis and M. A. Al-Sayed (2014) Frequency of some virulence associated genes among multidrugresistant Escherichia coli isolated from septicaemic broiler chicken. International journal of advanced research, 12(2):867-874.

Rajasekaran A. (2001) Characterization of fimbrial Ag's of Escherichia coli serotypes of chicken origin. M.V.Sc thesis submitted to Acharya N.G. Ranga Agricultural University, Rajendranagar Hyderabad - 500030.

Russo TA and Johnson JR. (2000). Proposal for a new inclusive designation for a new inclusive designation for extraintestinal pathogenic isolates of Escherichia coli (ExPEC) Journal of infectious diseases 181: 1753-1754.

Saha T, Guha C, Biswas U, Chakraborty D, Chakraborty G C, and Sahukhan T K (2007) Escherichia coli isolates from respiratory disease of broiler birds. Indian Veterinary Journal84: 915-917.

Schouler, C., Schaeffer B., Bree A. (2012) Diagnostic strategy for identifying avian pathogenic Escherichia coli based on four patterns of virulence genes J. Clin Microbiol. 501:673-78. 
Seifi, S., R. Khoshbakht and A. R. Atabak (2015) Antibiotic susceptibility, serotyping and pathogenicity evaluation of avian Escherichia coli isolated from broilers in northern Iran. Bulgarian Journal of Veterinary Medicine, 18 (2):173-179.

Shankar, T. V., A. Sharma and Y. Grover (2010) Studies on different virulence factors of avian pathogenic Escherichia coli. Haryana Veterinary science, 49:45-47.
Sharada R, Krishnappa G and Upendra H A 2001 Serological grouping and drug susceptibility of Escherichia coli strains from chicken. Indian Veterinary Journal 78: 78-79.

Veere Gowda B M, Krishna Murthy G V, Upadhye A S and Raghavan R. (1996) Serotypes of Escherichia coli from pathological condition in poultry and their antibiogram. Indian Veterinary journal73: 123-126.

\section{How to cite this article:}

Muglikar, D. M., I. H. Kalyani, Dhruv Desai, J. M. Patel, D. R. Patel, Pushpa Makwana and Solanki, J. B. 2019. Serotyping and Antimicrobial Susceptibility Pattern of Avian Pathogenic Escherichia coli. Int.J.Curr.Microbiol.App.Sci. 8(12): 505-511. doi: https://doi.org/10.20546/ijcmas.2019.812.067 